\title{
TRANSIÇÃO, SUSTENTABILIDADE E SISTEMAS AGROALIMENTARES NO BRASIL: PERSPECTIVAS E DISCUSSÕES
}

\author{
Cesar Buno Favarão ${ }^{1}$
}

iD $\underline{\text { https://orcid.org/0000-0001-7478-7131 }}$

SUZUKI, Júlio César; LAURENT, François; ARAÚJO, Valterlei Borges. Transições produtivas, agroecológicas e culturais no campo brasileiro. São Paulo: FFLCH/USP, 2019.

Um dos temas chaves que compõe a miríade de desafios postos com a agenda da sustentabilidade é a questão agroalimentar. No âmbito da produção científica, houve mudanças importantes nesse campo de estudos que, desde o século passado, vinha se dedicando a produzir um conhecimento quase que exclusivamente voltado a entender os sistemas agroalimentares a partir de uma perspectiva técnica e produtivista, respondendo às questões surgidas no âmbito do paradigma da Revolução Verde. Mais recentemente, no entanto, uma outra agenda de pesquisa emergiu procurando compreender os efeitos mais gerais causados pelas novas tendências de consumo e à globalização. Em partes, essas mudanças estruturais resultaram em novas formas de produção, comercialização e consumo, que são caracterizadas, fundamentalmente, por operar numa espécie de lógica contrária ao modelo dominante de reprodução do sistema agroalimentar mundial, ou seja, funcionam buscando superar e internalizar em suas dinâmicas, preocupações referentes às questões ambientais; às questões sociais, como inclusão produtiva e segurança alimentar; além dos aspectos relacionados à alimentação saudável.

Como bem apontam as diferentes perspectivas científicas que estudam as formas diferenciadas de estruturação dos sistemas agroalimentares, suas bases de reprodução socioeconômicas seriam caracterizadas por alguns aspectos, dos quais se destacam: a escala local de trocas e consumo; a qualidade e diferenciação dos produtos; e o desvelamento das relações mercantis, no qual o consumidor não é mero agente passivo, mas contribui ativamente para modelar as regras de mercado e formatar as etapas da cadeia alimentar, desde a produção até a comercialização. Muitas são as dimensões empíricas e objetos de estudos que compõem essa agenda de pesquisa, na qual a preocupação dos estudos comumente se volta à análise das formas orgânicas e agroecológicas de produção nos espaços rurais e urbanos, à produção artesanal de alimentos, aos mercados de produtos com certificações socioambientais, além dos estudos sobre movimentos sociais contestatórios que advogam em prol de uma cultura diferenciada de consumo e que, a partir daí, desenvolvem novos circuitos de comercialização. De maneira geral, pode-se dizer que a preocupação que está presente

\footnotetext{
${ }^{1}$ Doutorando e bolsista CAPES no Programa de Pós-Graduação em Planejamento e Gestão do Território da Universidade Federal do ABC.
} 
nessa agenda de pesquisa é o de identificar e compreender as novas relações socioeconômicas subjacentes aos sistemas agroalimentares diferenciados, mas também indagar se os padrões de produção, comercialização e consumo alimentar estariam experimentando um processo mais profundo de mudança no sentido de uma transição para um paradigma agroalimentar mais sustentável.

É, portanto, dentro desse panorama brevemente esboçado que podemos inserir a obra intitulada Transições produtivas, agroecológicas e culturais no campo brasileiro, organizada pelos pesquisadores Júlio César Suzuki, François Laurent e Valterlei Borges de Araújo, associados ao Programa de Pós-Graduação Integração da América Latina da USP (PROLAM). O livro, fruto de uma cooperação entre pesquisadores brasileiros e franceses, é composto por oito artigos que estão dispostos sem agrupamentos em partes ou seções, e que abordam estudos em diferentes territórios brasileiros.

No artigo introdutório, desenvolvido pelos organizadores, intitulado Transições produtivas, agroecológicas e culturais no campo brasileiro: desafios para o século XXI, mesmo sem apresentar uma discussão teórica aprofundada, são delineadas as problemáticas e o objetivo do livro: apresentar estudos que analisam as tendências mais recentes de mudanças no sistema agroalimentar, sobretudo do ponto de vista da produção, e a manifestação territorial desse processo, considerando os aspectos históricos, naturais e socioculturais, e as possíveis implicações para os temas da gestão e da governança.

Os artigos apresentados ao longo da publicação são bastante heterogêneos, principalmente no que diz respeito às perspectivas teóricas utilizadas. Fica evidente, em quase todos os estudos apresentados, com exceção do terceiro e do oitavo artigos, a preocupação em olhar para os territórios a partir de uma perspectiva diacrônica, evidenciando como determinados processos históricos estão na base das mudanças recentes nas formas de apropriação dos recursos naturais. É o que faz, por exemplo, o segundo artigo que abre a série de estudos de caso do livro, no qual os autores descrevem a construção da morfologia social e econômica de alguns municípios do sul do Pará a partir do século XIX, evidenciando como as características dos diferentes grupos sociais que foram ocupando o território, influenciados posteriormente pelas políticas de Estado após a segunda metade do século XX, determinaram um tipo de apropriação territorial baseada na modernização econômica e tecnológica, sendo a pecuária a principal atividade econômica norteadora desse processo ao longo do tempo.

Seguindo nesta mesma linha, o quarto artigo busca evidenciar também como determinados processos históricos estão na base da evolução do cultivo do cacau no sul da Bahia e como hoje se conforma uma produção agroecológica que contrasta com as formas de dominação personalista que tradicionalmente ainda marcam a produção do cacau na região. Como apontam os autores, a produção 
agroecológica do cacau, ainda que em menor escala, se conforma inovadora nos aspectos das relações de trabalho, do meio ambiente e acesso aos mercados por pequenos produtores. O quinto estudo apresentado no livro utiliza-se da perspectiva histórica para analisar como os processos de reconversão produtiva na região do sul do estado do Rio Grande do Sul, conduzidos pelo cultivo da soja e pela prática da silvicultura mais "moderna", avançam sobre as áreas de pastagem natural dos pampas, implicando o que os autores vão chamar de vulnerabilidades aos meios de vida dos pecuaristas de corte tradicionais da região.

Já o sexto artigo e o sétimo artigo se valem da análise de aspectos históricos, para estabelecer, mais especificamente, a relação entre território e mercados. No primeiro deles, os autores discutem como a identidade cultural de determinados grupos sociais subjazem às "bacias de produção" do arroz no estado do Rio Grande do Sul e desse modo embasam as estratégias produtivas baseadas em construções simbólicas associadas ao território. Já no segundo, analisa-se as dificuldades dos pequenos produtores familiares da Quarta Colônia em associar os elementos típicos deste território como as relações sociais referentes à tradição italiana - à produção de queijo, de maneira a possibilitar a inserção formal dos produtores em cadeias de comercialização mais amplas.

Para finalizar, o terceiro artigo e o oitavo artigo fogem um pouco da abordagem histórica que caracteriza os estudos citados anteriormente. No primeiro, os autores analisam, a partir de dados espaciais, a dinâmica de uso do solo no município de Paragominas no Pará, entre os anos de 20042013, e apontam para as mudanças nos processos de desmatamento no município induzidas pelas políticas federais de combate ao desmatamento e por restrições comerciais, sobretudo a partir de 2007, e como as características naturais são cruciais para lógica de ocupação do espaço e para as estratégias econômicas. Já no segundo artigo, os autores analisam os conflitos entre pescadores, Estado e iniciativa privada, decorrentes dos problemas socioambientais causados pela expansão portuária. Como atentam os autores, esse processo engendrou efeitos desagregadores na reprodução social do grupo de pescadores da comunidade da Ilha Diana, mas também, foi responsável por desencadear formas de resistência dessa comunidade que apontam para uma retomada e ressignificação de suas tradições e costumes.

O principal mérito do livro está justamente em sua contribuição para a compreensão desta diversidade de experiências econômicas nas regiões interioranas brasileiras vis-à-vis as mudanças e tendências mais gerais de produção e consumo agroalimentar - experiências estas que se manifestam de maneira heterogênea, dada a diversidade e disparidades territoriais inerentes à formação histórica do Brasil. Por outro lado, os estudos carecem de um diálogo mais sistemático, com correntes teóricas importantes que tratam especialmente do sistema agroalimentar e da própria literatura territorial. Só para citar um exemplo, não são feitas menções nem referências à literatura que estuda as Redes Alimentares Alternativas (RAA), os Sistemas Agroalimentares Alternativos e as Cadeias Curtas de 
Abastecimento. Essa literatura, que já vem produzindo reflexões sobre a temática há algum tempo, oferece uma perspectiva que compreende as mudanças nos sistemas agroalimentares como parte de uma sociabilidade reflexiva entre agentes pertencentes a diferentes campos sociais como o Estado, a sociedade civil e o mercado, que gradativamente vão conformando novas relações materiais e simbólicas que se diferenciam da produção agroalimentar convencional e, dessa forma, estruturam novos padrões de produção e consumo no sistema agroalimentar. O leitor se beneficiaria bastante de um diálogo, mesmo que crítico, entre as várias abordagens.

Outro aspecto a ser mencionado, é que, apesar do termo transição figurar no título do livro, pouco se discute acerca de tais processos. Há mesmo falta de uma definição a embasar a ideia de transição. Na ausência de um conceito ou categoria, a palavra transição ao longo da obra aparece inserida em ideias mais gerais como: "transição da vegetação", "transição de uso do solo" etc.; ou seja, sempre subentendida como processos ecológicos pontuais que estão na base de determinadas formas de produção. Mas o que dizer a respeito das injunções entre estes processos e outros determinantes das mudanças analisadas, e que, ao menos de certa forma, condicionam seu alcance e seu sentido? Como se vê, é vasto o campo de questões que se abre a partir dos temas e dos problemas abordados no livro, ainda que nem todas as respostas estejam (aliás, nem poderiam estar) nele. 